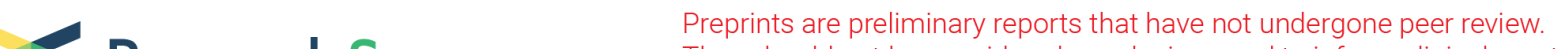 $\begin{array}{ll}\text { Research Square } & \text { They should not be considered conclusive, used to inform clinical practice, } \\ \text { or referenced by the media as validated information. }\end{array}$
}

\section{FH ALERT: A feasibility study of a novel approach to identify patients with familial hypercholesterolemia}

Felix Fath ( $\square$ felix.fath@t-online.de )

SYNLAB Holding Germany GmbH, SYNLAB Academy

Andreas Bengeser

SYNLAB Holding Germany GmbH

Mathias Barresi

SYNLAB Holding Germany GmbH

\section{Priska Binner}

SYNLAB Holding Germany $\mathrm{GmbH}$

\section{Stefanie Schwab}

SYNLAB MCC Human Genetics Mannheim GmbH

\section{Kausik Ray}

Imperial Centre for Cardiovascular Disease Prevention, Department of Primary Care and Public Health, Imperial College London

\section{Bernhard Krämer}

Vth Department of Medicine (Nephrology, Hypertensiology, Rheumatology, Endocrinology, Diabetology), Medical Faculty Mannheim, University of Heidelberg

\section{Uwe Fraass}

Amgen (Germany)

\section{Winfried März}

SYNLAB Holding Germany GmbH, SYNLAB Academy

\section{Research Article}

Keywords: Nephrology, Hypertensiology, Rheumatology, Endocrinology, Diabetology, LDL-C, SYNLAB

Posted Date: December 2nd, 2020

DOl: https://doi.org/10.21203/rs.3.rs-108034/v1

License: (c) (i) This work is licensed under a Creative Commons Attribution 4.0 International License. Read Full License 


\section{FH ALERT:}

A feasibility study of a novel approach to identify patients with familial hypercholesterolemia

Felix Fath a,b , Andreas Bengeser ${ }^{c}$, Mathias Barresic, Priska Binner ${ }^{c}$, Stefanie Schwab $^{d}$, Kausik K. Ray ${ }^{\mathrm{e}}$, Bernhard K. Krämer ${ }^{\mathrm{b}, \mathrm{f}}$, Uwe Fraass ${ }^{\mathrm{g}}$, Winfried März ${ }^{\mathrm{a}, \mathrm{b}, \mathrm{h}, \mathrm{i}}$

a SYNLAB Holding Germany GmbH, SYNLAB Academy, Mannheim, Germany

b $V^{\text {th }}$ Department of Medicine (Nephrology, Hypertensiology, Rheumatology, Endocrinology, Diabetology), Medical Faculty Mannheim, University of Heidelberg, Mannheim, Germany

c SYNLAB Holding Germany GmbH, Augsburg, Germany

d SYNLAB MCC Human Genetics Mannheim GmbH, Mannheim, Germany

e Imperial Centre for Cardiovascular Disease Prevention, Department of Primary Care and Public Health, Imperial College London, London UK

f European Center for Angioscience ECAS, Medical Faculty Mannheim, University of Heidelberg, Mannheim, Germany

$g$ Amgen $\mathrm{GmbH}$, Munich, Germany

h Clinical Institute of Medical and Chemical Laboratory Diagnostics Medical University of Graz, Austria

i D.A.CH Society Prevention of Cardiovascular Diseases e.V., Hamburg, Germany

\section{Corresponding author:}

Felix Fath, Ortstraße 24, 69469 Weinheim

Phone: +4915783931994, E-Mail: felix.fath@t-online.de 


\section{Abstract}

Background and aims. Diagnosis rates of familial hypercholesterolemia $(\mathrm{FH})$ remain low. We implemented FH ALERT to assess whether alerting physicians for the possibility of $\mathrm{FH}$ impacted additional diagnostic activity.

Methods. The study was conducted from SYNLAB laboratory Weiden (Bavaria). Beyond common reporting of LDL-C or TC, 1,411 physicians covering approximately a population of 1.5 million people were eligible to receive an alert letter $(A L)$ including information on $\mathrm{FH}$, if laboratory results exceeded thresholds as follows: adults LDL-C $\geq 190-250 \mathrm{mg} / \mathrm{dl}$ (to convert into $\mathrm{mmol} / \mathrm{l}$ multiply with 0,0259 ), TC $\geq 250$ to $\leq 310 \mathrm{mg} / \mathrm{dl}$ (probable suspicion); LDL-C $>250 \mathrm{mg} / \mathrm{dll}$ and TC $>310 \mathrm{mg} / \mathrm{dll}$ (strong suspicion). Persons below 18 years were alerted for LDL-C $\geq 140 \mathrm{mg} / \mathrm{dl}$ and TC $\geq 200 \mathrm{mg} / \mathrm{dl}$ (strong suspicion). Patients above 60 years were excluded. Our readouts were characteristics of involved physicians, rate of ALs issued, acceptance, and subsequent diagnostic activity.

Results. Physicians were mainly general practitioners in ambulatory care. $75 \%$ of the ordered tests were for TC, $25 \%$ for LDL-C. We issued 3,512 ALs ( $5 \%$ of tests). $86 \%$ of eligible physicians stayed with the initiative, $32.7 \%$ were alerted, and $70 \%$ were positive upon call-center survey. We registered 101 new visitors of www.fhscore.eu and sent out 93 kits for genetics. Thereof, 26 were returned and 5 patients were positive for $\mathrm{FH}$.

Conclusions. Although physicians appeared open to our approach, recommendations were hardly translated into action. The reasons behind this are elusive. Further education is required, and our simple alerting system may not suffice to improve $\mathrm{FH}$ detection in the community. 


\section{Introduction}

Elevated low-density lipoprotein cholesterol (LDL-C) is among the most important causes of atherosclerosis ${ }^{1}$. Genetic epidemiological and interventional studies have shown a continuous relationship between LDL cholesterol and the incidence of atherosclerosis-related vascular events ${ }^{1}$.

Familial hypercholesterolemia $(\mathrm{FH})$ is a genetic disorder of LDL-C metabolism, mainly caused by mutations in the genes encoding the $L D L$ receptor $(L D L R)$, apolipoprotein B100 (APOB) or proprotein convertase subtilisin/kexin type 9 (PCSK9). $\mathrm{FH}$ is inherited in an autosomal dominant manner, meaning that $50 \%$ of the descendants of a heterozygote parent are affected ${ }^{2}$. $\mathrm{FH}$ is the most frequent autosomal dominant genetic disease encountered in adults with a global prevalence estimated at between 1:200-1:300 and more common among populations with founder effects ${ }^{3}$. $\mathrm{FH}$ is characterized by pronounced elevations of plasma LDL-C as early as in childhood and premature onset of coronary heart disease ${ }^{2}$. Roughly 2 percent of individuals with an LDL-C above $190 \mathrm{mg} / \mathrm{dL}$ (to convert into $\mathrm{mmol} / \mathrm{l}$ multiply with 0,0259 ) suffer from $\mathrm{FH}^{4}$. Homozygous $\mathrm{FH}(\mathrm{HoFH})$ frequently results in cardiovascular events in the first decade of life, and left untreated those with HoFH may die before the age of 20 years ${ }^{5}$. In heterozygous $(\mathrm{HeFH})$ patients the additional risk of cardiovascular events is $50 \%$ in men up to the age of 50 and $30 \%$ in women up to the age of 606 .

Despite all available data detection remains low. For instance the prevalence rate of $\mathrm{HeFH}$ is approximately 1:300, which entails more than 250,000 patients in Germany ${ }^{6}$, yet the current diagnosis rate is estimated to be between 1 to $2 \%{ }^{3}$. Unidentified and untreated patients on average lose 15 to 21 years of life ${ }^{7}$. Registry data from the Netherlands have shown that an early screening strategy together with effective and early use of statin therapy to reduce LDL-C can reduce the cardiovascular risk associated with $\mathrm{FH}$ similar to that of the general population ${ }^{8}$. Thus, it is crucial that patients are identified early in life. Although, there are several clinical algorithms which help to identify patients with $\mathrm{FH}^{9} 1011$, they are underutilised in clinical practice. Moreover, these algorithms can be used to increase the pre-test probability of a positive genetic test ${ }^{12}$. The clinical value of genetic diagnostics of $\mathrm{FH}$ has been underscored by guidelines and expert consensus in the United States 13,14, Europe ${ }^{15,16}$, and Germany ${ }^{17}$, yet, utilization of genetic testing remains poor. To facilitate the diagnosis of $\mathrm{FH}$ and given that this condition is dependent upon ascertainment of an elevated LDL-C measurement, we designed a pilot study (FH ALERT) to serve as the 
interface between a clinical laboratory receiving blood samples for lipid measurements and the ambulatory outpatient care, to assess whether a decision support protocol was feasible, acceptable, and improved detection rates compared to historical records. Here we report the results of this pilot study to evaluate feasibility and acceptance of this approach in a German outpatient care environment. 


\section{Materials and Methods}

\section{Setting}

We included all ambulatory care physicians (general practitioners and specialists across all disciplines) referring their laboratory samples to the SYNLAB Medical Care Center (MCC) Weiden GmbH which is located in Bavaria, Germany. We chose MCC Weiden $\mathrm{GmbH}$ because it is one of the biggest SYNLAB core laboratories in Germany. All patients aged 60 and below visiting participating physicians who were being evaluated for elevated LDL-C or total cholesterol (TC) measurements were eligible. The study was conducted between March 15, 2018 and June 15, 2018 and approved by the Ethics Committee II of the Medical Faculty Mannheim, Heidelberg University, Theodor- Kutzer-Ufer 1-3, 68167 Mannheim (reference number 2018849R-MA). As this was a retrospective evaluation of findings generated during regular patient care and no study specific procedures were conducted, the abovementioned ethics committee did not consider it necessary to obtain individual informed consents. All methods were carried out in accordance with relevant guidelines and regulations.

\section{Procedures}

Beyond the regular laboratory results, participating physicians received an alert letter $(A L)$ once TC or LDL-C levels exceeded predefined threshold values (Figure 1). The ALs also included scientific information about $\mathrm{FH}$ and the further diagnostic options including genetic testing.

We used six different threshold values to trigger an $\mathrm{AL}$ (Table 1). We distinguished among two categories with different wording, namely "suspicion of FH" in adults belonging to the LDL-C threshold category I or TC threshold category I as well as "strong suspicion of FH" in children and in adults belonging to LDL-C threshold II and/or TC threshold II. (Table I). LDL-C was used as the primary criterion to trigger reports, TC was used in cases in which LDL-C was not available. We recommended the Dutch Lipid Clinic Network (DLCN) score to estimate the pre-test probability of a positive genetic test, with a test score of $\geq 6$ indicating for genetic testing. Approximately two weeks before initiation, we announced FH ALERT by an initiation letter to all physicians regularly referring tests to the SYNLAB MCC Weiden GmbH. This document described background and aims, design and procedures of the project. 
The initiation letter and each subsequent $A L$ informed the participating physician that they had the choice to opt-out from the project at any time.

The software extracting TC or LDL-C from the laboratory information system to produce the ALs was written by CSMed GmbH, Darmstadt, Germany. We established a call center which was specifically instructed and available to participating physicians to provide further information on the diagnoses of $\mathrm{FH}$ if requested (inbound calls). The call center was operated by IMS Health $\mathrm{GmbH} \&$ Co. OHG, Bensheim, Germany. The ALs usually arrived the day following the regular report. They included in depth information on the diagnosis of $\mathrm{FH}$, advice how to use the DLCN score ${ }^{11}$, how to initiate genetic testing, and named lipid specialists in the surroundings of the patients' residential address. Any medical decisions regarding further diagnostic and therapeutic measures were completely left to the discretion of the responsible physicians (Figure 1).

Physicians who received at least one AL were contacted pro-actively by the call center and asked to assess the FH Alert project using a standardized questionnaire. Physicians were also encouraged to express their criticism and to propose improvements of the procedures.

\section{Genetic testing}

Current guidelines and expert opinion suggest that the diagnosis of $\mathrm{FH}$ is established by genetic testing if accessible ${ }^{13-17}$. To achieve seamless access to genetic testing for $\mathrm{FH}$, we offered physicians the facilities at the SYNLAB Center of Human Genetics in Mannheim, Germany. Interested physicians were provided with kits (including request and consent forms and material for sampling) upon request. We monitored the number of genetic tests requested during the FH ALERT project until 6.5 months after the conclusion of the project on June 15, 2018. This accounted for delays in ordering genetic tests due to waiting for the patients' next appointments, education of patients or receiving their informed consent.

Patients' DNA was isolated from a blood sample and then analyzed by next generation sequencing. Following library preparation with TruSight Rapid Capture technology and bridge amplification, the sample was sequenced on an Illumina NextSeq 500 instrument. Coverage of the ROI was $>98 \%$, reading depth a minimum of 100 -fold. We examined the following loci: LDLR, APOB, PCSK9, LDLRAP, SORT1, NPC1L1, STAP1, APOE, ABCG5, ABCG8, DHCR24, LIPA, CYP27A1, and DHCR7. In addition, 
the $L D L R$ gene was also evaluated for copy number variation by multiplex ligationdependent probe amplification. Variants were classified according to current American College of Medical Genetics and Genomics (ACMG) guidelines ${ }^{18}$. Results were classified as inconspicuous, polygenic hypercholesterolemia and classically monogenic.

\section{Outcomes}

This study used the following readouts: characteristics of the physicians involved, number of ALs issued in comparison to the number of TC and/or LDL-C, acceptance by physicians, further diagnostic activity including genetic testing.

\section{Statistics}

Statistics is descriptive. Beyond the algorithm to generate alerting reports, CSMed $\mathrm{GmbH}$ also provided a documentation tool and a customized statistics module to evaluate FH ALERT. All calculations were performed with Microsoft ${ }^{\circledR}$ Excel $^{\circledR} 2016$ (Version: MSO (16.0.9126.2282) 32-Bit). The frequency of the use of the FH score online tool was tracked with Google Analytics.

Sources of Funding

FH ALERT was initiated by SYNLAB Holding Germany $\mathrm{GmbH}$ and supported by Amgen $\mathrm{GmbH}$. Expenses of upcoming costs and dedicated workflow were divided equally between project partners. 


\section{Results}

Characteristics of the physicians involved

During the project period 1,411 physicians/institutions ordered at least one analysis of any parameter from the SYNLAB MCC Weiden. They were mainly in ambulatory care (general practitioner or medical specialist), but also included occupational health departments of companies or health care institutions. Most letters were issued to general practitioners, followed by internists while paediatricians, nephrologists, dermatologists and gynaecologists contributed marginally (Figure 2).

\section{Alert letters generated}

During the project period of three months, 193,715 samples were analyzed by the SYNLAB MCC Weiden GmbH, and 75,431 TC and/or LDL-C examinations were performed. In our observation period, TC and/or LDL-C were therewith the fourth most frequent tests ordered, ranking just behind alanine aminotransferase (ALAT), aspartate aminotransferase (ASAT) and thyroid stimulating hormone (TSH). Overall, 3,512 (4.7\%) ALs were issued. In 885 cases (25.2\% of 3512 ) the ALs were triggered by LDLC with or without TC, whereas in 2,627 cases $(74.8 \%$ of 3512$)$ TC only triggered the ALs. Amongst those, approximately 95\% fell into to category I. 154 (4.4\%) of all ALs were generated patients below 18 years of age. In category II, all 181 ALs were for adults. The average age of alerted persons was 48 years in total, 50 years in women and 47 years in men (Table 2).

On average, there were 2.49 ALs per physician, when calculated based on 1,411 (total participating physicians) and 7.6 ALs per physician in relation to physicians who received at least one AL. 462 of participating physicians - predominantly general practitioners and internists - were alerted and received at least one AL (32,74\%). 37 medium frequently alerted physicians received 3 to 4 ALs $(8.01 \%$ of alerted physicians), 48 frequently alerted physicians 5 to 9 ALs ( $10.39 \%$ of alerted physicians) and 121 high frequently alerted physicians were alerted 10 times or more $(26.19 \%$ of alerted physicians). 


\section{Acceptance}

Only 200 physicians chose to opt out from the project and 1,211 physicians participated for all 3 months, corresponding to an opt-out rate of $14,2 \% ; 32.74 \%$ of all physicians received at least one AL (Table 2).

In the survey conducted by the call center, FH ALERT was evaluated positively by approximately $70 \%$ of respondents, $23 \%$ did not finally know how to classify and $7 \%$ had a negative opinion about FH ALERT. The most frequent criticism arose regarding to the amount of paperwork caused by ALs, followed by a lack of additional time to look through the ALs.

The FH score website was visited 101 times due to the FH ALERT project; 31 visitors recurred at least once, $88 \mathrm{FH}$ score questionnaires were completed whereof $45 \mathrm{had}$ a result of $\geq 3$ (Table 2).

Further diagnostic activity including genetic testing

During the FH ALERT project 93 sampling kits for genetic testing were sent out to 60 physicians and 26 were returned for analysis within the active period and 6.5 months beyond. Of these, 10 samples were inconspicuous, 3 showed variants most likely not related to hypercholesterolemia, 8 samples showed variants or combinations of variants which we classified as polygenic hypercholesterolemia, and 5 samples showed at least one variant that we deemed causal for familial hypercholesterolemia. Among these, 3 were heterozygous for LDLR mutations (Table 3) 


\section{Discussion}

We successfully established a novel channel of information exchange between the clinical laboratory and requesting physicians. We found that this approach was generally welcome to the majority of the medical community participating. However, we also observed that this poorly translated into further diagnostic steps - as far as this process was visible for us - as they are recommended by international and national expert opinion or guidelines ${ }^{13-16}$.

Even though TC and LDL-C are amongst the most frequently ordered tests in ambulatory care, the diagnosis rate of $\mathrm{FH}$ remains low in Germany, and in many other countries ${ }^{3}$. We started by assuming physicians commonly do not pay attention to extreme TC or LDL-C results included in conventional laboratory reports and hardly consider the diagnosis of $\mathrm{FH}$, and if so, rarely or no consecutive action or further diagnostic steps follow. To enhance awareness for pathologic lipid parameters, we decided to specifically alert physicians once TC or LDL-C exceeded threshold values at which the probability of $\mathrm{FH}$ is deemed to be high.

\section{Alert letters generated}

Approximately $5 \%$ of all the samples tested triggered an alert. This confirms that in the population studied, our thresholds defined a subgroup of samples beyond the $95^{\text {th }}$ percentile of either LDL-C or TC. Most of these samples fell in threshold category I (LDL-C 190-250, TC $250-310 \mathrm{mg} / \mathrm{dl}$ in adults or LDL-C $\geq 140 \mathrm{mg} / \mathrm{dl}$, TC $\geq 200 \mathrm{mg} / \mathrm{dl}$ in children), only $5 \%$ fell in category II (LDL-C $>250 \mathrm{mg} / \mathrm{dl}$ or TC $>310 \mathrm{mg} / \mathrm{dl}$ ). At an estimated prevalence rate of $\mathrm{FH}$ of 1:300 in the general population and under the assumption that there were no $\mathrm{FH}$ patients amongst those below the pre-defined cutoffs, approximately $250 \mathrm{FH}$ patients $(75,000$ tests divided by 300 ) should have been amongst those who triggered an $\mathrm{AL}$, the ratio of true $\mathrm{FH}$ patients being 1 in 14 amongst those who are above threshold I. Others estimated this ratio even lower: Among coronary heart disease-free participants of prospective cohort studies only 24 of 1386 persons with $L D L-C \geq 190$ had genetically confirmed $\mathrm{FH}$, suggesting a ratio of 1 in 58 ${ }^{4}$, indicating a substantial overlap of LDL-C concentrations between FH patients and otherwise elevated LDL-C 4,19,20. Therefore, molecular diagnostics has been recommended to distinguish between these two groups ${ }^{14}$.

Only one quarter of the ALs was triggered by LDL-C with or without assessment of TC, the remaining ones by TC only. This stands in contrast to previous and current 
guidelines which define LDL-C as the primary treatment goal ${ }^{15,21-23}$ and demonstrates that further efforts are warranted to educate physicians to place emphasis on LDL-C instead of TC.

Of the participating physicians, who were predominantly general practitioners and internists, $32.74 \%$ received at least one report. This suggests that a small proportion of physicians include cholesterol and/or LDL-C testing into their standard practice of care. The majority of physicians may thus waive for screening for high cholesterol and/or to conduct state of the art risk assessment as it would comply with guidelines 15,16,21-23. However, at least theoretically there may be physicians caring for patients with well controlled LDL levels or not being at elevated risk according to previous screening. As a consequence of the clustering of ALs to one third of the physicians only it may be worth limiting FH ALERT specifically to general practitioners and internists who regularly order TC and/or LDL-C in the future. In Germany, nephrologists and dialysis centres often provide care for patients with lipid disorders. However, they did not substantially contribute to the total number of ALs, on the one hand because they are small in number, on the other hand because their lipid patients may be well controlled (Figure 2). Only few ALs originated from paediatricians, indicating that TC and/or LDL cholesterol are infrequently measured in patients $<18$ years and that opportunities to identify $\mathrm{FH}$ at a young age are vastly missed in Germany. Thus, it appears that the single initiation letter that we issued was not sufficient to provide a broad awareness of the significance of LDL-C. Other reasons to waive cholesterol testing may be that it has been disputed that the cost-effectiveness of systematic risk factor screening in the absence of vascular disease is still a matter of debate ${ }^{21}$ or that lipid lowering therapy would not immediately have been considered in a given patient.

\section{Acceptance}

Amongst all participating physicians, 200 (14\%) decided to opt out. We believe that this discontinuation rate is reasonable since we offered a hitherto completely unknown service. As the most common reason to withdraw physicians quoted that the ALs produced too much additional paperwork and due to this often lead to lacking time in their practice to even read individual ALs. Other withdrawing physicians said that it would need too much time to follow the advice provided with the ALs, disregarding that a clear diagnosis could facilitate treatment decisions and patients' adherence in the future and might therefore allow time savings alongside. Refinement of the FH ALERT 
strategy in the future will therefore have to resolve this criticism, for instance by cumulating results within one weekly report. However, of the physicians who finished the pilot study almost more than two thirds assessed the initiative as positive, and only less than $10 \%$ had a negative opinion about the FH ALERT project.

Further diagnostic activity including genetic testing

The 462 physicians who received an alert ordered 93 sampling kits for genetic testing, of which $26(27.96 \%)$ were ultimately returned for genetic testing. We recorded the number of genetic tests requested until 6.5 months after the conclusion of FH ALERT, but evidently the time between ordering kits and actually carrying out the test may be longer so that actual number of tests may yet be slightly higher.

We noted 101 new visitors on the www.fhscore.eu website. Under the assumption that there was an overlap between the 101 new visitors on the website and the 60 physicians who ordered kits for genetic testing, it may be reasonable and conservative to assume that 120 physicians amongst the 462 who had received an AL responded in any of the two ways to the FH ALERT initiative. Thus, the overall response rate may be $25 \%$ or more. Since to our knowledge the design of FH ALERT is unprecedented, a comparison to established bench marks is hard to accomplish. In any case, however, the response rates achieved here by far exceed the response rates known from untargeted mailings which are usually $1 \%$ or less.

Of the 26 requests for genetic testing 10 were inconspicuous, 3 showed variants most likely not related to hypercholesterolemia, 8 samples showed variants or combinations of variants which we classified as polygenic and $5(19 \%)$ showed at least one variant that we deemed causal for familial hypercholesterolemia. This may be less than obtained in specialized lipid clinics, where we found causal mutations in approximately $80 \%$ of patients with a DLCN Score of 6 or more ${ }^{12}$. Further, the 5 true FH cases make up approximately $2 \%$ only of the number of patients that would theoretically have $\mathrm{FH}$ in our study (see above). Even if one would still account for the cases in which we considered the genetic findings as polygenic hypercholesterolemia, this would increase to no more than 5\%. Overall, genetic testing for $\mathrm{FH}$ was thus taken up poorly, although the environment for cascade screening, which is recommended as costeffective for identifying $\mathrm{FH}$ patients and preventing vascular disease (reviewed in ${ }^{14}$ ), would be ideal in a rural area like the Upper Palatinate where the general practitioner usually oversees many generations of a family. However, if one assumes that those 
13 people who either received the diagnosis of genetic hypercholesterolemia or definite $\mathrm{FH}$ would gain 10 years of life each through intensive treatment, the FH ALERT pilot project would have saved 130 years of life and the effect would even be much larger if treating physicians went back to the families of the index patients to identify other affected individuals.

The reasons for the poor uptake of genetics may be manifold. Ordering genetic tests may have been uncommon in ambulatory care so far. Other reasons may include: lack of knowledge of $\mathrm{FH}$ amongst physicians, misbeliefs about the expenses or the reimbursement of genetic testing (genetic testing is not charged to the laboratory budget of physicians in Germany), lack of time, lack of diligence, low awareness of $\mathrm{FH}$ in the lay population, poor willingness of patients to agree into genetic testing. However, it is unlikely that the patients' attitudes would seriously compromise the use of genetic testing. Rather parents of affected children or patients have been open to genetic testing recognizing its benefit with little evidence for psychological impact ${ }^{24-29}$. Consequently, we consider proactive and comprehensive education of physicians of utmost importance to lead them up to a better understanding of the benefits of genetic testing. This is evidently not only true for genetic lipid disorders but applies to all disease areas in which genetic disease becomes symptomatic in adulthood.

Future directions

3,512 ALs ultimately lead to 26 genetic tests only. Despite this, we consider our pilot study successful, mainly because significant other diagnostic activity (visits to $\mathrm{FH}$ score website) developed during the project period. Also the high proportion of physicians rating $\mathrm{FH}$ positive has been encouraging and we are convinced that our novel strategy of communication between referrers and the laboratory holds considerable potential for the future.

Based on our experience, conceivable improvements are: i) reducing the amount of paperwork by consolidating individual alert letters to weekly cumulated alert letters; ii) generating increased awareness for TC/LDL-C earlier before starting the initiative by educational events and multiple initiation letters; iii) including medical societies and key opinion leaders in awareness activities; iv)increasing the frequency of calls by the call center to remind physicians to perform genetic testing and send back the genetics kits for analyses; v) yearly repetition of the initiative. 


\section{Limitations}

Limitations of this project are the exclusion of samples from patients above 60 years of age and the thresholds for ALs at the $95^{\text {th }}$ percentile of the TC and LDL-C distribution. The latter obviously will miss some FH patients (also including the treated ones), because having an LDL-C of less than $190 \mathrm{mg} / \mathrm{dl}$ does not rule out $\mathrm{FH}^{4}$. Further, we did not include samples coming from hospitals to which $\mathrm{FH}$ patients may present with acute coronary syndromes. The pilot study was restricted to three months only and to a rural area of Germany and may therefore not be representative. It is also a limitation that it was hard to place our findings into the context of similar studies because to the best of our knowledge there is no published report systematically evaluating our approach.

\section{Conclusions}

We conclude that bridging the interface between referring physicians and the laboratory by an innovative approach of communication is technically demanding, but feasible. Basically, our initiative was welcome and highly appreciated by the participating physicians. However, even individualized recommendations as they were provided with FH ALERT were not rigorously translated into concrete action. 


\section{References}

1 Ference, B. A. et al. Low-density lipoproteins cause atherosclerotic cardiovascular disease. 1. Evidence from genetic, epidemiologic, and clinical studies. A consensus statement from the European Atherosclerosis Society Consensus Panel. Eur Heart J 38, 2459-2472, doi:10.1093/eurheartj/ehx144 (2017).

2 Klose, G., Laufs, U., Marz, W. \& Windler, E. Familial hypercholesterolemia: developments in diagnosis and treatment. Deutsches Arzteblatt international 111, 523-529, doi:10.3238/arztebl.2014.0523 (2014).

3 Nordestgaard, B. G. et al. Familial hypercholesterolaemia is underdiagnosed and undertreated in the general population: guidance for clinicians to prevent coronary heart disease: consensus statement of the European Atherosclerosis Society. Eur Heart J 34, 3478-3490a, doi:10.1093/eurheartj/eht273 (2013).

4 Khera, A. V. et al. Diagnostic Yield and Clinical Utility of Sequencing Familial Hypercholesterolemia Genes in Patients With Severe Hypercholesterolemia. J Am Coll Cardiol 67, 2578-2589, doi:10.1016/j.jacc.2016.03.520 (2016).

5 Sanna, C. et al. Homozygous familial hypercholesterolemia in childhood: Genotype-phenotype description, established therapies and perspectives. Atherosclerosis 247, 97-104, doi:10.1016/j.atherosclerosis.2016.02.009 (2016).

6 Schmidt, N. et al. Familial hypercholesterolemia in primary care in Germany. Diabetes and cardiovascular risk evaluation: Targets and Essential Data for Commitment of Treatment (DETECT) study. Atherosclerosis 266, 24-30, doi:10.1016/j.atherosclerosis.2017.08.019 (2017).

7 Mundal, L. et al. Mortality among patients with familial hypercholesterolemia: a registry-based study in Norway, 1992-2010. Journal of the American Heart Association 3, e001236, doi:10.1161/JAHA.114.001236 (2014).

8 Versmissen, J. et al. Efficacy of statins in familial hypercholesterolaemia: a long term cohort study. BMJ 337, a2423 (2008).

9 Williams, R. R. et al. Diagnosing heterozygous familial hypercholesterolemia using new practical criteria validated by molecular genetics. Am J Cardiol 72, 171-176, doi:10.1016/0002-9149(93)90155-6 (1993). 
10 Risk of fatal coronary heart disease in familial hypercholesterolaemia. Scientific Steering Committee on behalf of the Simon Broome Register Group. BMJ 303, 893-896, doi:10.1136/bmj.303.6807.893 (1991).

11 Defesche, J. C., Lansberg, P. J., Umans-Eckenhausen, M. A. \& Kastelein, J. J. Advanced method for the identification of patients with inherited hypercholesterolemia. Seminars in vascular medicine 4, 59-65, doi:10.1055/s2004-822987 (2004).

12 Grenkowitz, T. et al. Clinical characterization and mutation spectrum of German patients with familial hypercholesterolemia. Atherosclerosis 253, 8893, doi:10.1016/j.atherosclerosis.2016.08.037 (2016).

13 Goldberg, A. C. et al. Familial hypercholesterolemia: screening, diagnosis and management of pediatric and adult patients: clinical guidance from the National Lipid Association Expert Panel on Familial Hypercholesterolemia. Journal of clinical lipidology 5, S1-8, doi:10.1016/j.jacl.2011.04.003 (2011).

14 Sturm, A. C. et al. Clinical Genetic Testing for Familial Hypercholesterolemia: JACC Scientific Expert Panel. J Am Coll Cardiol 72, 662-680, doi:10.1016/j.jacc.2018.05.044 (2018).

15 Catapano, A. L. et al. 2016 ESC/EAS Guidelines for the Management of Dyslipidaemias: The Task Force for the Management of Dyslipidaemias of the European Society of Cardiology (ESC) and European Atherosclerosis Society (EAS) Developed with the special contribution of the European Assocciation for Cardiovascular Prevention \& Rehabilitation (EACPR). Atherosclerosis 253, 281-344, doi:10.1016/j.atherosclerosis.2016.08.018 (2016).

16 Mach, F. et al. 2019 ESC/EAS Guidelines for the management of dyslipidaemias: lipid modification to reduce cardiovascular risk. Eur Heart J, doi:10.1093/eurheartj/ehz455 (2019).

17 Deutsche Gesellschaft für Allgemeinmedizin. Hausärztliche Risikoberatung zur kardiovaskulären Prävention. S3-Leitlinie. AWMF-Register-Nr. 053-024, DEGAM-Leitlinie Nr. 19, https://www.degam.de/files/Inhalte/LeitlinienInhalte/Dokumente/DEGAM-S3-Leitlinien/053024 Risikoberatung\%20kardiovaskul.\%20Praevention/053024l Hausa\%CC\%88rztliche Risikoberatung kardivaskula\%CC\%88re Praev ention 29-08-2018.pdf (2017). 
18 Richards, S. et al. Standards and guidelines for the interpretation of sequence variants: a joint consensus recommendation of the American College of Medical Genetics and Genomics and the Association for Molecular Pathology. Genet Med 17, 405-424, doi:10.1038/gim.2015.30 (2015).

19 Huijgen, R., Hutten, B. A., Kindt, I., Vissers, M. N. \& Kastelein, J. J. Discriminative ability of LDL-cholesterol to identify patients with familial hypercholesterolemia: a cross-sectional study in 26,406 individuals tested for genetic FH. Circ Cardiovasc Genet 5, 354-359, doi:10.1161/CIRCGENETICS.111.962456 (2012).

20 Wald, D. S. et al. Child-Parent Familial Hypercholesterolemia Screening in Primary Care. N Engl J Med 375, 1628-1637, doi:10.1056/NEJMoa1602777 (2016).

21 Piepoli, M. F. et al. 2016 European Guidelines on cardiovascular disease prevention in clinical practice: The Sixth Joint Task Force of the European Society of Cardiology and Other Societies on Cardiovascular Disease Prevention in Clinical Practice (constituted by representatives of 10 societies and by invited experts)Developed with the special contribution of the European Association for Cardiovascular Prevention \& Rehabilitation (EACPR). Eur Heart J 37, 2315-2381, doi:10.1093/eurheartj/ehw106 (2016).

22 Stone, N. J. et al. 2013 ACC/AHA Guideline on the Treatment of Blood Cholesterol to Reduce Atherosclerotic Cardiovascular Risk in Adults: A Report of the American College of Cardiology/American Heart Association Task Force on Practice Guidelines. Circulation, doi:10.1161/01.cir.0000437738.63853.7a (2013).

23 Grundy, S. M. et al. 2018 AHA/ACC/AACVPR/AAPA/ABC/ACPM/ADA/AGS/APhA/ASPC/NLA/PCNA Guideline on the Management of Blood Cholesterol. Circulation, CIR0000000000000625, doi:10.1161/CIR.0000000000000625 (2018).

24 Umans-Eckenhausen, M. A., Defesche, J. C., van Dam, M. J. \& Kastelein, J. J. Long-term compliance with lipid-lowering medication after genetic screening for familial hypercholesterolemia. Archives of internal medicine 163, 65-68 (2003).

25 Marteau, T. et al. Psychological impact of genetic testing for familial hypercholesterolemia within a previously aware population: a randomized 
controlled trial. Am J Med Genet A 128A, 285-293, doi:10.1002/ajmg.a.30102 (2004).

26 Claassen, L., Henneman, L., van der Weijden, T., Marteau, T. M. \& Timmermans, D. R. Being at risk for cardiovascular disease: perceptions and preventive behavior in people with and without a known genetic predisposition. Psychol Health Med 17, 511-521, doi:10.1080/13548506.2011.644246 (2012).

27 Jenkins, N. et al. How do index patients participating in genetic screening programmes for familial hypercholesterolemia $(\mathrm{FH})$ interpret their DNA results? A UK-based qualitative interview study. Patient Educ Couns 90, 372377, doi:10.1016/j.pec.2011.09.002 (2013).

28 Hallowell, N. et al. A qualitative study of patients' perceptions of the value of molecular diagnosis for familial hypercholesterolemia (FH). J Community Genet 8, 45-52, doi:10.1007/s12687-016-0286-0 (2017).

29 Keenan, K. F. et al. Parents' views of genetic testing and treatment of familial hypercholesterolemia in children: a qualitative study. J Community Genet 10, 129-141, doi:10.1007/s12687-018-0373-5 (2019).

30 Ballantyne, C. M., Vega, G. L., East, C., Richards, G. \& Grundy, S. M. Lowdensity lipoprotein metabolism in cerebrotendinous xanthomatosis. Metabolism 36, 270-276, doi:10.1016/0026-0495(87)90187-9 (1987).

31 Cohen, J. C. et al. Multiple rare variants in NPC1L1 associated with reduced sterol absorption and plasma low-density lipoprotein levels. Proceedings of the National Academy of Sciences of the United States of America 103, 18101815, doi:10.1073/pnas.0508483103 (2006).

32 Wang, L. J. et al. Molecular characterization of the NPC1L1 variants identified from cholesterol low absorbers. J Biol Chem 286, 7397-7408, doi:10.1074/jbc.M110.178368 (2011).

33 Bennet, A. M. et al. Association of apolipoprotein E genotypes with lipid levels and coronary risk. Jama 298, 1300-1311 (2007).

34 Wang, L. R., Mclntyre, A. D. \& Hegele, R. A. Complex genetic architecture in severe hypobetalipoproteinemia. Lipids in health and disease 17, 48, doi:10.1186/s12944-018-0680-1 (2018).

35 Argyri, L. et al. Molecular basis for increased risk for late-onset Alzheimer disease due to the naturally occurring L28P mutation in apolipoprotein E4. $J$ Biol Chem 289, 12931-12945, doi:10.1074/jbc.M113.538124 (2014). 
36 Kamboh, M. I. et al. A novel mutation in the apolipoprotein E gene (APOE*4 Pittsburgh) is associated with the risk of late-onset Alzheimer's disease. Neurosci Lett 263, 129-132, doi:10.1016/s0304-3940(99)00129-9 (1999).

37 Hansel, B. et al. Premature atherosclerosis is not systematic in phytosterolemic patients: severe hypercholesterolemia as a confounding factor in five subjects. Atherosclerosis 234, 162-168, doi:10.1016/j.atherosclerosis.2014.02.030 (2014).

38 Buonuomo, P. S. et al. Timely diagnosis of sitosterolemia by next generation sequencing in two children with severe hypercholesterolemia. Atherosclerosis 262, 71-77, doi:10.1016/j.atherosclerosis.2017.05.002 (2017).

39 Alves, A. C., Etxebarria, A., Soutar, A. K., Martin, C. \& Bourbon, M. Novel functional $A P O B$ mutations outside LDL-binding region causing familial hypercholesterolaemia. Hum Mol Genet 23, 1817-1828, doi:10.1093/hmg/ddt573 (2014).

40 Motazacker, M. M. et al. Evidence of a polygenic origin of extreme highdensity lipoprotein cholesterol levels. Arterioscler Thromb Vasc Bio/ 33, 15211528, doi:10.1161/ATVBAHA.113.301505 (2013).

41 Pirillo, A. et al. Spectrum of mutations in Italian patients with familial hypercholesterolemia: New results from the LIPIGEN study. Atherosclerosis. Supplements 29, 17-24, doi:10.1016/j.atherosclerosissup.2017.07.002 (2017).

42 Dron, J. S. \& Hegele, R. A. Complexity of mechanisms among human proprotein convertase subtilisin-kexin type 9 variants. Curr Opin Lipidol 28, 161-169, doi:10.1097/MOL.0000000000000386 (2017).

43 Holla, O. L. et al. Effects of intronic mutations in the LDLR gene on pre-mRNA splicing: Comparison of wet-lab and bioinformatics analyses. Molecular genetics and metabolism 96, 245-252, doi:10.1016/j.ymgme.2008.12.014 (2009).

44 Maxwell, K. N. et al. Evaluation of ACMG-Guideline-Based Variant Classification of Cancer Susceptibility and Non-Cancer-Associated Genes in Families Affected by Breast Cancer. American journal of human genetics 98 , 801-817, doi:10.1016/j.ajhg.2016.02.024 (2016).

45 Marmontel, O. et al. Single, short in-del, and copy number variations detection in monogenic dyslipidemia using a next-generation sequencing strategy. Clinical genetics 94, 132-140, doi:10.1111/cge.13250 (2018). 
46 Bertolini, S. et al. Spectrum of mutations and phenotypic expression in patients with autosomal dominant hypercholesterolemia identified in Italy. Atherosclerosis 227, 342-348, doi:10.1016/j.atherosclerosis.2013.01.007 (2013).

47 Hobbs, H. H., Brown, M. S. \& Goldstein, J. L. Molecular genetics of the LDL receptor gene in familial hypercholesterolemia. Hum Mutat 1, 445-466, doi:10.1002/humu.1380010602 (1992).

48 Cassanelli, S. et al. A 'de novo' point mutation of the low-density lipoprotein receptor gene in an Italian subject with primary hypercholesterolemia. Clinical genetics 53, 391-395, doi:10.1111/j.1399-0004.1998.tb02752.x (1998). 


\section{Acknowledgments}

We thank the physicians in the Upper Palatinate area for participating in FH ALERT. We also thank the staff of the SYNLAB Medical Care Center Weiden GmbH, of CSMed GmbH, Darmstadt, Germany, of IMS Health GmbH \& Co. OHG, Bensheim, Germany, and of the SYNLAB Logistics Department, Augsburg, Germany. KKR acknowledges support from the NIHR Imperial Biomedical Research Centre.

\section{Author contributions}

WM and UF conceived the study, interpreted the results and critically reviewed the manuscript. FF implemented the study and did statistical analysis. FF and WM and are responsible for the manuscript. $A B$ and $M B$ implemented the dedicated FH ALERT workflow within the SYNLAB laboratory information systems and contributed to the statistical analysis. SS and PB provided genetic analyses and variant annotations. BKK contributed to the ethics committee application and critically reviewed the manuscript. KKR critically reviewed the manuscript. All authors take full responsibility of the whole manuscript.

\section{Additional Information}

\section{Competing Interests statement}

Mr. Fath reports employment with SYNLAB Holding Germany GmbH, SYNLAB Academy. SYNLAB Academy received grants from Amgen $\mathrm{GmbH}$, during the conduct of the project FH ALERT; grants from Akcea Therapeutics Germany GmbH, outside the submitted work.

Dr. Binner, Mr. Bengeser and Mr. Barresi report employment with SYNLAB Holding Germany $\mathrm{GmbH}$, outside the submitted work.

Mrs. Schwab reports employment with SYNLAB MCC Human Genetics Mannheim $\mathrm{GmbH}$, outside the submitted work.

Dr. Krämer has nothing to disclose. 
Dr. Fraass is employed by Amgen $\mathrm{GmbH}$ and additionally holds stock, outside the submitted work.

Dr. März reports grants and personal fees from AMGEN, grants and other from SYNLAB Holding Deutschland $\mathrm{GmbH}$, during the conduct of the study; grants from Siemens Healthineers, grants and personal fees from Aegerion Pharmaceuticals, grants and personal fees from AMGEN, grants from Astrazeneca, grants and personal fees from Sanofi, grants and personal fees from Alexion Pharmaceuticals, grants and personal fees from BASF, grants and personal fees from Abbott Diagnostics, grants and personal fees from Numares AG, grants and personal fees from Berlin-Chemie, other from SYNLAB Holding Deutschland $\mathrm{GmbH}$, grants and personal fees from Akcea Therapeutics, grants from Bayer Vital $\mathrm{GmbH}$, grants from bestbion $\mathrm{dx} \mathrm{GmbH}$, grants from Boehringer Ingelheim Pharma $\mathrm{GmbH}$ Co $\mathrm{KG}$, grants from Immundiagnostik $\mathrm{GmbH}$, grants from Merck Chemicals $\mathrm{GmbH}$, grants from MSD Sharp and Dohme $\mathrm{GmbH}$, grants and personal fees from Novartis Pharma $\mathrm{GmbH}$, grants from Olink Proteomics, outside the submitted work.

Dr. Ray reports receiving investigator initiated research grants to his institution from Amgen, Sanofi, Regeneron, MSD, Pfizer, Daiichi Sankyo and honoraria for consultancy from Amgen, Sanofi, Regeneron, MSD, Pfizer, Astra Zeneca, Lilly, Medicines Company, Kowa, IONIS, Takeda, Novo Nordisk, Boehringer Ingelheim, Esperion, Cipla, Algorithm, Abbvie, Resverlogix, Cerenis, Novartis, Akcea, Silence Therapeutics.

\section{Financial support}

The initiative FH ALERT was financed equally by SYNLAB Holding Deutschland GmbH and Amgen $\mathrm{GmbH}$.

\section{Legends}

Figure 1. Schematic representation of procedures of FH ALERT. Alerting letters (ALs) were issued to treating physicians once total cholesterol (TC) or LDL-C scored above predefined threshold values. In addition to TC or LDL-C the ALs provided information about $\mathrm{FH}$ and further diagnostic options including genetic testing. 
Figure 2. Distribution of Alerting letters (ALs) to specialist groups. Most ALs were issued to general practitioners, followed by internists while paediatricians, nephrologists, dermatologists and gynaecologists contributed marginally.

Table 1. Overview of defined thresholds triggering alert letters. Beside the thresholds, alert categories and associated severity levels are illustrated.

Table 2. FH ALERT's pilot initiative key results. Data describes general information, distribution of alerts, acceptance, feedback, and genetic testing.

Table 3. Genetic findings in 26 samples obtained from FH ALERT. Subdivided according to the categories variants most likely not relevant to hypercholesterolemia, possibly relevant to hypercholesterolemia and familial hypercholesterolemia all findings are described by diagnosis, gene, variant, zygosity and ACMG (American College of Medical Genetics and Genomics) class as well as associated remarks in addition. 


\section{Tables}

Table 1. Overview of alert letters' triggering thresholds

\begin{tabular}{|c|c|c|c|c|}
\hline & $\begin{array}{l}\text { Children } \\
\text { (<18 years })\end{array}$ & Suspicion of FH & $\begin{array}{c}\text { Adults } \\
(\geq 18 \leq 60 \text { years })\end{array}$ & Suspicion of $\mathrm{FH}$ \\
\hline LDL C threshold 1 & \multirow[t]{2}{*}{$\geq 140 \mathrm{mg} / \mathrm{dL}$} & \multirow{2}{*}{ Strong } & $\geq 190 \mathrm{mg} / \mathrm{dL}$ & probable \\
\hline LDL C threshold 2 & & & $>250 \mathrm{mg} / \mathrm{dL}$ & strong \\
\hline $\begin{array}{l}\text { TC threshold } 1 \\
\text { (if } L D L C \text { is not available) }\end{array}$ & \multirow{2}{*}{$\geq 200 \mathrm{mg} / \mathrm{dL}$} & \multirow{2}{*}{ Strong } & $\geq 250 \mathrm{mg} / \mathrm{dL}$ & probable \\
\hline $\begin{array}{l}\text { TC threshold } 2 \\
\text { (if } L D L C \text { is not available) }\end{array}$ & & & $>310 \mathrm{mg} / \mathrm{dL}$ & strong \\
\hline
\end{tabular}


Table 2. FH ALERT's pilot initiative key results

Period of time: 12 weeks

Absolute values

Cholesterol examinations

Alert letters, $n(\%)$

Distribution of alerts

Category I

Adults with probable suspicion

Children with strong suspicion

Sum, $\mathrm{n}(\%)$

$3,331(94.85)$

thereof LDL C, $\mathrm{n}(\%)$

thereof TC, $\mathrm{n}(\%)$

$2,493(74.84)$

Category II

Adults with strong suspicion, $\mathrm{n}(\%)$

$181(5.15)$

thereof LDL C, $\mathrm{n}(\%)$

$47(25.97)$

thereof TC, $\mathrm{n}(\%)$

$134(74.03)$

Age

Patients $<18$ years, $\mathrm{n}(\%)$

Patients $\geq 18 \leq 60$ years, $n(\%)$

$154(4.38)$

Average age (total/ female/ male, years)

Acceptance and Feedback

Total number of clients of MCC Weiden $\mathrm{GmbH}, \mathrm{n}(\%)$

Clients with Opt-out, n (\%)

Alerted clients

Clients with alert letters, $\mathrm{n}(\%)$

Alert letters per client (total/alerted clients)

$462(32.74)$

$2.49 / 7.60$

$\geq 10$ alert letters (Opt-in, cum.), n (\%)

$\geq 5 \leq 9$ alert letters (Opt-in, cum.), n (\%)

$121(26.19)$

$48(10.39)$

$\geq 3 \leq 4$ alert letters (Opt-in, cum.), n (\%)

$37(8.01)$

Positive reaction by caller, $\mathrm{n}(\%)$

$370(69.94)$

Negative reaction by caller, $\mathrm{n}(\%)$

$38(7.18)$

Undifferentiated reaction by caller, $\mathrm{n}(\%)$

$121(22.87)$

FH Score

New visitors/recurring visitors

Completed questionnaires

Questionnaires > 3

Genetic testing

Requested genetic test kits

Returned genetic test kits, n (\%)

$26(27.96 \%)$


Table 3. Genetic findings in 26 samples obtained from FH ALERT.

\begin{tabular}{|c|c|c|c|c|c|}
\hline Diagnosis & Gene & Variant & Zygosity & $\begin{array}{l}\text { ACMGa }^{a} \\
\text { class }\end{array}$ & Remarks \\
\hline \multicolumn{6}{|c|}{ Variants most likely not relevant to hypercholesterolemia } \\
\hline & CYP27A1 & c.1494G>C, p.(Lys498Asn) & Het $^{\mathrm{b}}$ & 3 & $\begin{array}{l}\text { Recessive mutations of CYP21A1 responsible for CTX', not } \\
\text { described in the literature, in silico possibly damaging, but } \\
\text { Lys } 498 \text { poorly conserved and CTX patients have typically low } \\
\text { to normal LDL C }{ }^{30}\end{array}$ \\
\hline & NPC1L1 & c.448C>T, p.(Leu150Phe) & Het & 3 & $\begin{array}{l}\text { Leu150 poorly conserved, not contained in mutation } \\
\text { databases, not described in the literature, in silico benign }\end{array}$ \\
\hline & NPC1L1 & C1496C>T, p.(Thr499Met) & Het & & $\begin{array}{l}\text { Thr499 poorly conserved, pathogenic according to HGMDd, } \\
\text { loss of function variant, reduced intestinal cholesterol } \\
\text { absorption } 31,32\end{array}$ \\
\hline \multicolumn{6}{|c|}{ Possibly relevant to hypercholesterolemia } \\
\hline Genetic HC & $A P O E$ & c.526C>T, p.(Arg176Cys) & APOE2/3 & & Type III HLPe? \\
\hline \multirow[t]{4}{*}{ Genetic HC } & $A P O E$ & c.388T>C, p.Cys130Arg & APOE3/4 & & LDL-C increased by apoE4 33 \\
\hline & ABCG5 & c.431T>C, p.(Val144Ala) & Het & 3 & $\begin{array}{l}\text { Val144 strongly conserved, low frequency, located in the "P- } \\
\text { loop containing nucleoside triphosphate domain" of ABCG8, } \\
\text { in silico disease causing, no reports in the literature, } \\
\text { increased cholesterol absorption? }\end{array}$ \\
\hline & DHCR24 & c. $231+19 \mathrm{G}>\mathrm{C}, \mathrm{p} .(?)$ & Het & 3 & $\begin{array}{l}\text { Intronic variant, in silico prediction of aberrant mRNA splicing, } \\
\text { no reports in the literature }\end{array}$ \\
\hline & PCSK 9 & c.1327G >A, p.(Ala443Thr) & Het & 3 & Ala443 poorly conserved, no relationship to elevated LDL-C ${ }^{34}$ \\
\hline Genetic HC & $A B C G 8$ & c.712G>A, p.(Glu238Lys) & Het & 3 & $\begin{array}{l}\text { Glu238 strongly conserved, located in the "P-loop containing } \\
\text { nucleoside triphosphate domain" of } A B C G 8 \text {, in silico disease } \\
\text { causing, loss of acceptor splice site of exon } 6 \text {, no reports in } \\
\text { the literature, increased cholesterol absorption? }\end{array}$ \\
\hline \multirow[t]{2}{*}{ Genetic HC } & $A P O E$ & c.526C>T, p.(Arg176Cys) & APOE2/3 & & Type III HLP? \\
\hline & $A B C G 8$ & c. $1832 \mathrm{G}>\mathrm{A}, \mathrm{p} .($ Arg611Lys) & Het & 3 & Arg611 poorly conserved, increased cholesterol absorption? \\
\hline Genetic HC & SORT1 & c.43C>T, p.(Pro15Ser) & Het & 3 & $\begin{array}{l}\text { Pro155 poorly conserved, not contained in mutation } \\
\text { databases, low allele frequency, in silico controversial }\end{array}$ \\
\hline
\end{tabular}




\begin{tabular}{|c|c|c|c|c|c|}
\hline & CYP27A1 & c.4391G>A, p.(Arg164Gin) & Het & 3 & $\begin{array}{l}\text { Arg164 highly conserved, in silico controversial, low allele } \\
\text { frequency, not described in the literature }\end{array}$ \\
\hline Genetic HC & $A P O E$ & $\begin{array}{l}\text { c.388T>C, p.Cys130Arg, } \\
\text { c.137T>C, p.(Leu46Pro) }\end{array}$ & $\begin{array}{l}\text { APOE3/4 } \\
\text { P }\end{array}$ & & $\begin{array}{l}\text { ApoE-Pittsburg, possibly associated with Alzheimer's disease } \\
35,36 \text {, association with cholesterol elusive }\end{array}$ \\
\hline \multirow[t]{3}{*}{ Genetic HC } & $A B C G 8$ & c.1083G >A, p. $\left(\operatorname{Trp} 361^{\star}\right)$ & Het. & & $\begin{array}{l}\text { Causes stop of the translation, causal in recessive } \\
\text { sitosterolemia }{ }^{37,38} \text {, increased cholesterol absorption ? }\end{array}$ \\
\hline & APOE & c388T>C, p.(Cys130Arg) & APOE3/4 & & LDL-C increased by apoE4 ${ }^{33}$ \\
\hline & $A P O B$ & $\begin{array}{l}\text { c.3337G }>C, \\
\text { p.(Asp1113His) }\end{array}$ & Het & 3 & $\begin{array}{l}\text { Asp1113 poorly conserved, controversial in silico, } \\
\text { p.Arg1164Thr in the vicinity considered causal in one } \\
\text { publication } 39\end{array}$ \\
\hline Genetic HC & NPC1L1 & $\begin{array}{l}\text { Haplotype c.529G }>A \\
\text { p.Val177lle, c.661C>T } \\
\text { p.(His221Tyr) } \\
\text { c811_812delGCinsTT } \\
\text { p.(Ala271Phe) }\end{array}$ & Het & 3 & $\begin{array}{l}\text { c.529G }>A \text { and c.661C }>\text { T reported associated with high HDL- } \\
\text { C and TC } 40\end{array}$ \\
\hline \multicolumn{6}{|c|}{ Familial hypercholesterolemia } \\
\hline \multirow[t]{2}{*}{ Het FH } & ABCG5 & c.1829A>C, p.(Glu610Ala) & Het & 3 & $\begin{array}{l}\text { Low frequency, in silico disease causing, high cholesterol } \\
\text { absorption? }\end{array}$ \\
\hline & $A P O B$ & c.2630c>T, p.(Pro877Leu) & Het & 3 & $\begin{array}{l}\text { Pro877 strongly conserved, in silico disease causing, no } \\
\text { reports in the literature, binding deficient apo B-100? }\end{array}$ \\
\hline \multirow[t]{2}{*}{ Het FH } & PCSK9 & $\begin{array}{l}\text { c.60_65dupGCTGCT, } \\
\text { p.(Leu22_Leu23dup) }\end{array}$ & Het & 3 & Gain of function variant 41,42 \\
\hline & $A P O E$ & c388T>C, p.(Cys130Arg) & APOE3/4 & & LDL-C increased by apoE4 ${ }^{33}$ \\
\hline \multirow[t]{3}{*}{ Het FH } & $L D L R$ & c.190+4_190+7del, p.? & Het & 3 & $\begin{array}{l}4 \text { bp deletion within the donor splice of exon } 4 \text { likely likely to } \\
\text { cause abberant splicing of the } L D L R m R N A \text { according to in } \\
\text { silico prediction, individual base changes at c. } 190+4 \text { and } \\
\text { c. } 190+5 \text { listed as pathogenic on HGMD, abberant splicing of } \\
\text { these variants proven experimentally } 43\end{array}$ \\
\hline & $A P O B$ & $\begin{array}{l}\text { c.663966641del, } \\
\text { p.(Asp2213del) }\end{array}$ & Het & 3 & $\begin{array}{l}\text { Variant previously detected in a patient with } \mathrm{FH} \text {, causality still } \\
\text { controversial }{ }^{39,44}\end{array}$ \\
\hline & $A P O B$ & $\begin{array}{l}\text { c.9242G>A, } \\
\text { p.(Ser3081Asn) }\end{array}$ & Het & 3 & Significance of the variant unclear $\left.{ }^{45}\right]$ \\
\hline
\end{tabular}




\begin{tabular}{|c|c|c|c|c|c|}
\hline Het FH & $L D L R$ & c.798T>A, p.(Asp266Glu) & Het & & $\begin{array}{l}\text { Asp266 highly conserved, disease causing according to } \\
\text { HGMD and Clinvar, causal according to the literature } 46,47\end{array}$ \\
\hline \multirow[t]{2}{*}{ Het. FH } & $L D L R$ & $\begin{array}{l}\text { c.10_delinsCGGGGGCTG } \\
\text { GAAATTGCGCTGGACCG } \\
\text { TCGCC, c.10_delins31 } \\
\text { p.(Trp4_Ala13delinsArgGly } \\
\text { LeuGlu } \\
\text { IleAlaLeuAspArgArg), } \\
\text { p.(Trp4_Ala13delins10) }\end{array}$ & Het & 4 & $\begin{array}{l}\text { Exchange of } 10 \text { amino acids in exon } 1 \text {, in silico pathogenic, } \\
\text { not described in the literature nor in databases, multiple base } \\
\text { changes have been described as pathogenic at position c. } 28 \text {; } \\
\text { they replace Trp } 10 \text { (which is affected by the current mutation } \\
\text { as well) by other amino acids } 46,48\end{array}$ \\
\hline & $A P O E$ & c388T>C, p.(Cys130Arg) & APOE3/4 & & LDL-C increased by apoE4 ${ }^{33}$ \\
\hline
\end{tabular}

Abbreviations

a ACMG: American College of Medical Genetics and Genomics

b Het: heterozygous

c CTX cerebrotendinous xanrhomartosis

d Human Gene Mutation Database

e HLP: hyperlipoproteinemia 


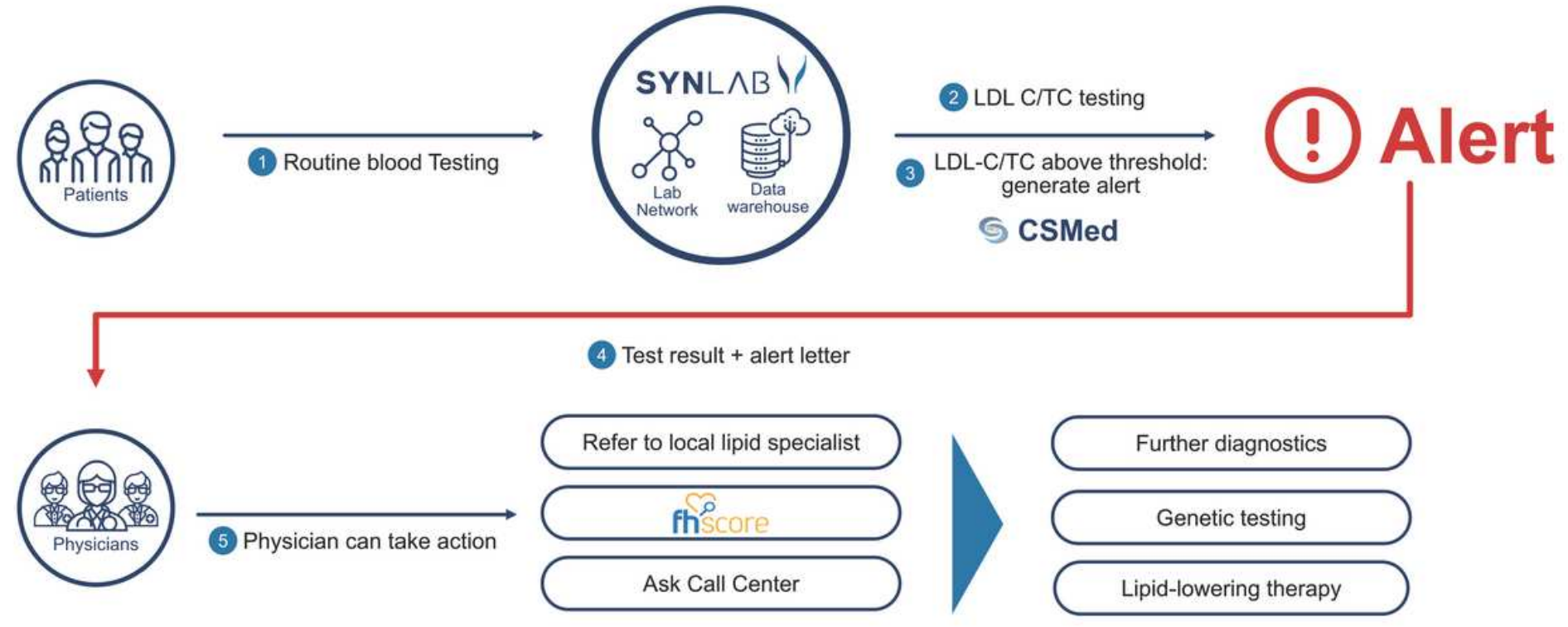

\section{Figure 1}

Schematic representation of procedures of FH ALERT. Alerting letters (ALs) were issued to treating physicians once total cholesterol (TC) or LDL-C scored above predefined threshold values. In addition to TC or LDL-C the ALs provided information about FH and further diagnostic options including genetic testing. 


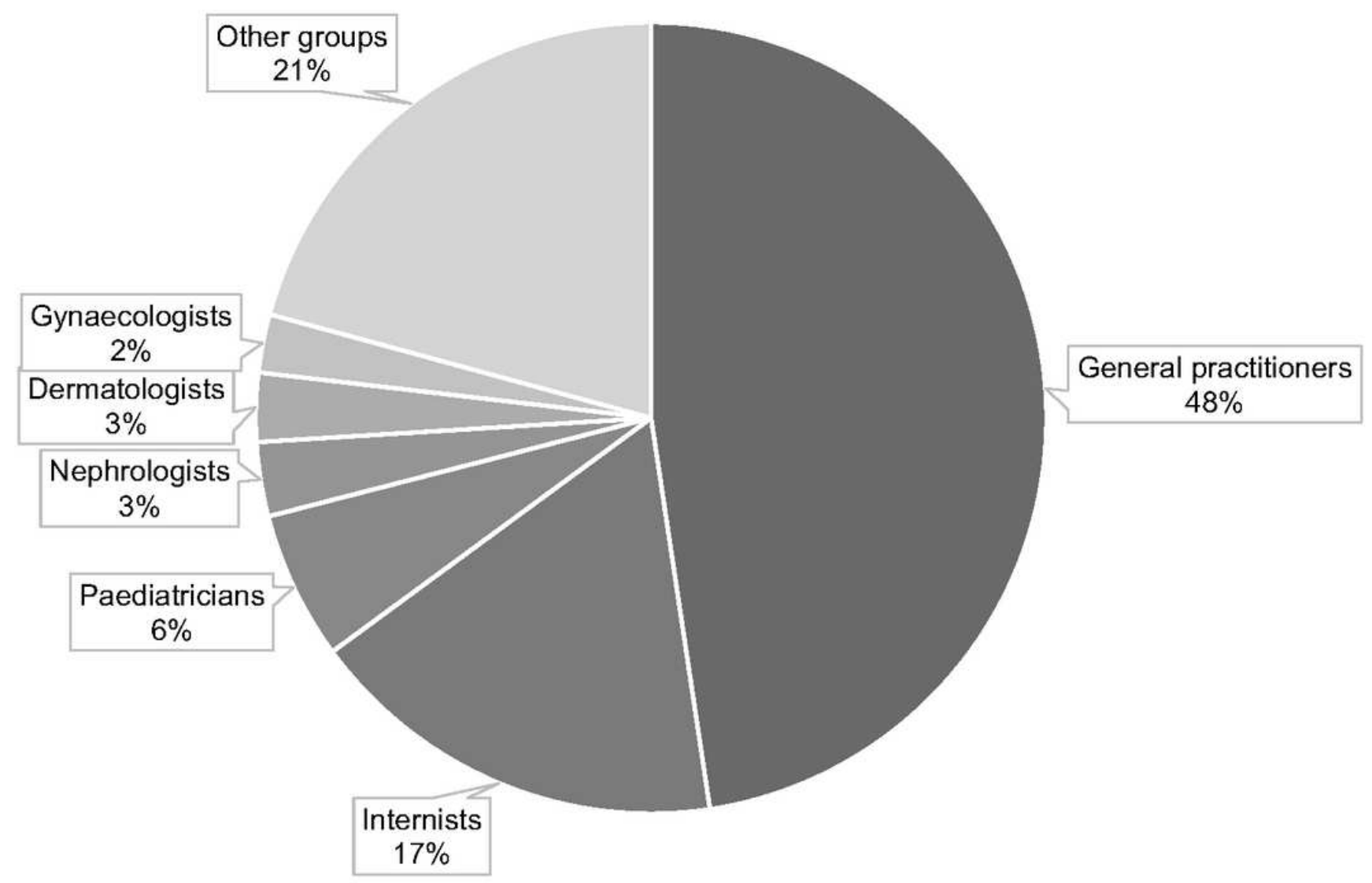

Figure 2

Distribution of Alerting letters (ALs) to specialist groups. Most ALs were issued to general practitioners, followed by internists while paediatricians, nephrologists, dermatologists and gynaecologists contributed marginally. 